\title{
Resistance training and sarcopenia
}

\author{
Training di resistenza e sarcopenia
}

\author{
Francesco Giallauria1, Antonio Cittadini', Neil Andrew Smart², Carlo Vigorito1 \\ 1 Department of Translational Medical Sciences, Division of Internal Medicine and Cardiac Rehabilitation, \\ Federico II University of Naples, Italy \\ 2 School of Science and Technology, University of New England, Armidale, NSW 2351, Australia
}

\begin{abstract}
Aging is inexorably accompanied by a progressive decline of muscle mass, quality and strength. The resulting condition has been termed sarcopenia. Age-related sarcopenia can be accelerated by a variety of factors including changes in the hormonal milieu, inactivity, poor nutrition, chronic illness, and loss of integrity and function in the peripheral and central nervous systems. The downstream mechanisms by which these risk factors cause sarcopenia are not completely understood. Exercise training (particularly resistance training) has long been identified as the most promising method for increasing muscle mass and strength among older people. New interventions aimed at preventing muscle atrophy, promoting muscle growth and ultimately, maintaining muscle functions during aging are discussed. Understanding how age affects muscle-related gene expression, protein recycling and resynthesis, post-translational modification and turnover will be crucial to identify new treatment options.
\end{abstract}

\section{Riassunto}

L'invecchiamento è inesorabilmente accompagnato da un progressive declino della massa, della qualità e della forza muscolare. La conseguente condizione viene definita sarcopenia. La sarcopenia correlata all'invecchiamento può essere accelerata da una serie di fattori tra cui le modifiche degli equilibri ormonali, la sedentarietà, la scarsa nutrizione, le patologie croniche, e la perdita di integrità e funzione del sistema

Corresponding author: Francesco Giallauria, MD, PhD, Department of Translational Medical Sciences, Division of Internal Medicine and Cardiac Rehabilitation, Federico II University of Naples, Italy.

E-mail: giallauriafrancesco@gmail.com

Key words: Aging; sarcopenia; resistance training.

Parole chiave: Invecchiamento; sarcopenia; training di resistenza.

Received for publication: 18 April 2016

Accepted for publication: 26 April 2016

CC Copyright F. Giallauria et al., 2015

Tipografia PI-ME Editrice, Italy

Monaldi Archives for Chest Disease Cardiac Series 2015; 84:738

doi: $10.4081 /$ monaldi.2015.738

This article is distributed under the terms of the Creative Commons Attribution Noncommercial License (by-nc 4.0) which permits any noncommercial use, distribution, and reproduction in any medium, provided the original author(s) and source are credited. nervoso centrale e periferico. I meccanismi attraverso i quali questi fattori causano sarcopenia sono ancora non completamente chiari. L'esercizio fisico (in particolare il training di resistenza) è da tempo identificato come una delle più promettenti stratefie per aumentare la massa muscolare e la forza negli anziani. Interventi mirati a prevenire la atrofia muscolare, a promuovere la crescita muscolare e, in ultima analisi, preservare le funzioni muscolari durante l'invecchiamento verranno discussi. Comprendere come l'invecchiamento interferisce con l'espressione genica ai livello muscolare, con i sistemi di riciclo e resintesi proteica, con le modifiche post-traslatzionali e il turnover, sarà cruciale per identificare e implementare nuove strategie terapeutiche.

\section{Introduction}

Aging is inexorably accompanied by a progressive decline of muscle mass, quality and strength. The resulting condition has been termed "sarcopenia", although for some authors this term should be reserved to the reduction of muscle mass [1]. The term of "sarcopenia" was first introduced in 1989 to describe a progressive, generalized loss of skeletal muscle mass and accompanying decline in muscle strength and performance with increasing age. Age-related sarcopenia can be accelerated by a variety of factors including hormonal milieu, inactivity, poor nutrition, chronic illness, and loss of integrity in the peripheral and central nervous systems (Table 1). Sarcopenia is associated with many negative outcomes, such as disability, frailty, comorbidities, hospital admissions and death [2].

The downstream mechanisms by which these risk factors cause sarcopenia are not completely understood. Some of the critical pathways for muscle repair and homeostasis have been recently outlined. In the future, these mechanisms may become the target for new interventions aimed at preventing muscle atrophy, promoting muscle growth and ultimately, maintaining muscle function during aging. Results from twin studies, suggest that the lifetime peak muscle mass which occurs between the second and the third decade of life, and the rate of age-associated decline in muscle mass/strength during aging are in part genetically determined [2]. Accordingly, scientists have proposed that sarcopenia does not merely result from "wear and tear" but rather from a highly ordered and regulated process that ultimately results in muscle proteolysis not counterbalanced by appropriate synthesis of new contractile proteins. Exercise training has long been identified as the most promising method for increasing muscle mass and strength among older people.

\section{Mechanisms leading to sarcopenia}

Sarcopenia is a multifactorial condition. Factors that contribute to the occurrence of sarcopenia include protein metabolism, motor units, hormones and lifestyle. 
Table 1. Potential causes of age-related loss of muscle mass.

Sedentary lifestyle

Poor nutritional intake, especially essential amino acids and creatine

Reduced levels of and responsiveness to trophic hormones

- Growth hormone

- Androgens

- Insulin-like growth factor 1 (IGF-1)

- Dehydroepiandrosterone sulfate (DHEAS)

- 25-hydroxy ergocalciferol (vitamin D)

Imbalance between anabolic and catabolic protein metabolism

Loss of motoneurons

Microvascular disease

Excessive and unopposed oxidative stress

Pro-inflammatory state

There is some evidence suggesting that during the early phase of sarcopenia, muscle protein synthesis increases, perhaps because the accelerated catabolism makes aminoacids available [3]. This early state is characterized by impaired oxidative defense, decreased activity of mitochondrial enzymes activity and dysregulation of genes implicated in energy metabolism, DNA repair, stress response, immune response, and proteasome-mediated protein degradation [3].

In the mature stage of the sarcopenic process, the synthesis rate of myofibrillar proteins is reduced, while sarcoplasmic proteins are relatively spaired [4]. Interestingly, in spite of the dramatic reduction in myosin heavy chain synthesis, transcription is not affected, suggesting the existence of a defect at the post-transcriptional level [5]. Overall, age-related alterations in protein synthesis contribute to, but fail to completely explain the slow erosion of muscle protein mass that leads to overt sarcopenia.

The loss of alpha motor units from the spinal cord is thought to be the most crucial contributor to sarcopenia [6]. Age-related motor unit loss may contribute to sarcopenia, but seldom limits mobility or independence until a critical threshold is reached. Notably, together with motor unit loss, the increased size of the remaining motor units and the loss of muscle fibers have also been identified as significant contributing factors to sarcopenia [7].

Many hormones have metabolic effects on muscle mass and function. A convincing body of evidence indicates that the aging process alters the circulating concentrations of several important anabolic hormones [8].

Finally, physical inactivity and muscle disuse promote the loss of muscle mass and worsen the degree of sarcopenia [6]. Studies also show that the decline in food intake and protein consumption among the elderly contribute to muscle atrophy and the severity of sarcopenia [9].

\section{Exercise and nutrition: a combined strategy}

It remains to be elucidated how different mechanisms are mutually interfaced in regulating muscle protein metabolism. Some of the common pathways that regulate muscle protein synthesis/degradation and the complexity of their interventions are emerging [10]. The challenge for researchers is to identify, in the context of these pathways, new targets for interventions. Interestingly, only exercise and, to some extent, nutritional intervention have been successful in slowing down or reversing sarcopenia. Exercise and physical activity affect the homeostatic equilibrium of skeletal muscle throught multiple mechanisms, including stimulation of the anabolic hormones, up-regulation of antioxidant enzymes, reduced inflammation, improved muscle insulin sensitivity, and increased protein synthesis [10].
Thus, it is not surprising that physical activity when combined with good nutrition can contrast the development of sarcopenia. Interestingly, physical activity can have positive effects even in individuals affected by specific chronic conditions and regardless of any organ-specific functional parameters altered by the disease status.

Nutritional supplementation may have immediate clinical application for muscle wasting in individuals with limited intake of nutrients required for anabolic processes. The administration of amino acid and carbohydrate build blocks downregulate proteolysis and provide the material necessity for protein synthesis. However, there is some evidence that in frail older individuals, unless the nutritional supplementation is associated with exercise it may not be effective [11].

There is an urgent need to find other effective interventions that may target the molecular pathways that regulate muscle physiology. Increasingly our knowledge of the molecular mechanisms involved in the genesis of sarcopenia is the key to discover and test the effectiveness of these new interventions.

\section{Resistance training}

Resistance training has long been identified as the most promising method for increasing muscle mass and strength among older people (Table 2). Growing licterature have confirmed the effectiveness of resistance training in improving muscle mass, strength, balance and endurance among the elderly [10,11]. Yarasheski et al. [12] reported that resistance training could enormously enhance the rate of mixed muscle protein synthesis in physically frail older subjects. After 3 months of weight-lifting exercise, the muscle contractile protein synthesis rates in these sedentary seniors were greatly increased. In a randomized and placebo-controlled trial, including nursing home residents, 10 weeks of resistance training increased muscle crosses sectional area by $3-9 \%$ and improved muscle strength and performance in gait speed and stair climbing abilities [13]. Moreover, Frontera et al. [14] demonstrated that 2 weeks of resistance training could substantially promote extensor and flexor strength in older participants. In evaluating muscle protein breakdown during sarcopenia and aging, Fry et al. [15] found that regulators of muscle protein breakdown responded similarly in young and older adults following resistance training, suggesting that resistance training could slow the pace of sarcopenia. Therefore, resistance training could effectively improve or prevent sarcopenia among the elderly, via improvements in muscle mass and strength.

However, although in individuals $<80$ years of age current research has established the efficacy of progressive resistance training as a method to enhance muscle mass and functional capacity; in older population ( $\geq 80$ years old) additional evidence is needed examining inter-

Table 2. Benefits of resistance training in the elderly.

- Improved bone density and reduced symptoms of osteoarthritis

- Increased protein synthesis in the muscle

- Increased IGF-1

- Increased lean body mass

- Increased lean body mass

- Improved endurance

- Increased strength

- Decreased depression

- Base in activities of daily living

- Improved quality of sleep

- Fall prevention 
Table 3. Resistance training prescriptions.

\begin{tabular}{|c|c|c|}
\hline Warm-up and cool-down & Intensity & Frequency \\
\hline $\begin{array}{l}\text { Warm-up and cool-down periods should be longer } \\
\text { for elderly population. Optimal warm-up activities } \\
\text { should last at least } 15-20 \text { min, whereas } 10-15 \text { min } \\
\text { should be designated to the cool-down period. } \\
\text { It is important to stretch active muscles in both } \\
\text { periods, and the warm-up session should involve } \\
\text { lifting light weights. }\end{array}$ & $\begin{array}{l}\text { Exercise intensity should consider the individual's } \\
\text { heart rate and energy expenditure. During the } \\
\text { training sessions, seniors should move the } \\
\text { resistance through the entire range of motion } \\
\text { and avoid heavy lifting. }\end{array}$ & $\begin{array}{l}\text { 2-4 days per week. The average frequency } \\
\text { should be } 3 \text { days/week and the individual } \\
\text { should wait at least } 48 \text { hours between } \\
\text { training sessions. }\end{array}$ \\
\hline Duration & Rest periods and physical environments & Breathing \\
\hline 20-45 minutes & $\begin{array}{l}\text { Longer rest periods between exercise sessions } \\
\text { as well as safe physical environments are } \\
\text { imperative for seniors }\end{array}$ & $\begin{array}{l}\text { Seniors are encouraged not to hold their } \\
\text { breath during resistance training. Lifting } \\
\text { belts and abdominal strengthening } \\
\text { exercise may be used }\end{array}$ \\
\hline
\end{tabular}

vention techniques like progressive resistance training as a preventative measure for the risks and issues associated with sarcopenia. In addition, more studies are encouraged in order to discern the safest, most efficacious approach to implement a non-pharmacological approach (i.e., exercise intervention strategies) that might attenuate or reverse the effects of sarcopenia in very old populations ( $\geq 80$ years old). Sarcopenia may be part of the "normal" aging process but limiting or reducing its potentially deleterious effects can provide the mounting number of older individuals and the very old with a higher quality life, functional capacity, and independence for a longer period of time.

The effect of nutrition on metabolic and frailty syndromes associated to sarcopenia during resistance training has not been fully investigated. Therefore, future studies are encouraged for understanding whether combined strategies (nutritional supplementation + resistance training) are most beneficial.

\section{Exercise prescriptions}

When designing a resistance exercise program to manage sarcopenia, some specific clue for intervention should be adopted (Table 3 ). Generally, the goal is to gradually overload the muscles and make positive adaptations, such as improvement in muscle mass and function. In addition, particular attention should be paid to specific and normal aging-related physiological in order to avoid exercise-related injuries or severe outcomes.

Resistance training programs for sarcopenia should be dynamic and targeted to the major muscle groups using both concentric and eccentric movements. Exercise programs targeting lower extremity muscles should be prioritized because they are important in mobility, balance and gait.

\section{Conclusions}

Sarcopenia is a slow progressive process that leads to physical impairment in older persons. To date, many factors involved in the progression to sarcopenia have been identified but only recently have the mechanisms by which these factors dysregulate muscle catabolic/analbolic homeostasis started to be uncovered. A better understanding of the genetic and molecular mechanism implicated in the genesis of agerelated sarcopenia can substantially contribute to the accomplishment of this goal. More studies are also needed in order to identify the effect of different training programs, long-term responses, and the role of optimal nutrition to enhance the anabolic effects of resistance training.

\section{References}

1. Thomas DR. Loss of skeletal mass in aging: examining the relationship of starvation, sarcopenia and cachexia. Clin Nutr 2007; 26:389-99.

2. Rolland Y, Czerwinski S, Abellan Van Kan G, Morley JE, Cesari M, Onder G, et al. Sarcopenia: its assessment, etiology, pathogenesis, consequences and future perspectives. J Nutr Health Aging 2008;12:433-50.

3. Kimball SR, O'Malley JP, Anthony JC, et al. Assessment of biomarkers of protein anabolism in skeletal muscle during the life span of the rat: sarcopenia despite elevated protein synthesis. Am J Physiol Endocrinol Metab 2004;287:E772-E80.

4. Giresi PG, Stevenson E J, Theilhaber J, et al. Identification of a molecular signature of sarcopenia. Physiol Genomics. 2005;21:255-63.

5. Balagopal P, Rooyackers OE, Adey DB, Ades PA, Nair KS. Effects of aging on in vivo synthesis of skeletal muscle myosin heavychain and sarcoplasmic protein in humans. Am J Physiol 1997; 273(4 Pt 1):E790-800.

6. Roubenoff R. Sarcopenia and its implications for the elderly. Eur J Clin Nutr 2000;54(suppl. 3):S40-S7.

7. Sperling L. Evaluation of upper extremity function in 70 -year-old men and women. Scand J Rehabil Med 1980;12:139-44.

8. McIntire KL, Hoffman AR. The endocrine system and sarcopenia: potential therapeutic benefits. Curr Aging Sci 2011;4:298-305.

9. Greenlund LJ, Nair KS. Sarcopenia-consequences, mechanisms, and potential therapies. Mech Ageing Dev 2003;124:287-99.

10. Johnston AP, De Lisio M, Parise G. Resistance training, sarcopenia, and the mitochondrial theory of aging. Appl Physiol Nutr Metab 2008;33:191-9.

11. Morley JE. Weight loss in older persons: new therapeutic approaches. Curr Pharm Des 2007;13:3637-47.

12. Yarasheski KE, Pak-Loduca J, Hasten DL, et al. Resistance exercise training increases mixed muscle protein synthesis rate in frail women and men $>/=76$ yr old. Am J Physiol 1999;277(1 Pt 1):E118-25.

13. Fiatarone MA, O'Neill EF, Ryan ND, et al. Exercise training and nutritional supplementation for physical frailty in very elderly people. N Engl J Med 1994;330:1769-75.

14. Frontera WR, Meredith CN, O'Reilly KP, et al. Strength conditioning in older men: skeletal muscle hypertrophy and improved function. J Appl Physiol (1985). 1988;64:1038-44.

15. Fry CS, Drummond MJ, Glynn EL, et al. Skeletal muscle autophagy and protein breakdown following resistance exercise are similar in younger and older adults. J Gerontol A Biol Sci Med Sci 2013; 68:599-607. 